\title{
Stability Analysis of Rock Slope with Multilayer Weak Interlayer
}

\author{
Jinglong Li $\mathbb{D},{ }^{1,2}$ Bo Zhang, ${ }^{2}$ and Bin Sui ${ }^{2}$ \\ ${ }^{1}$ Key Laboratory of Geological Hazards on Three Gorges Reservoir Area (China Three Gorges University), Ministry of Education, \\ Yichang, Hubei 443002, China \\ ${ }^{2}$ School of Civil and Engineering, Shandong University, Jinan 250061, China \\ Correspondence should be addressed to Jinglong Li; lijl@sdu.edu.cn
}

Received 14 April 2021; Revised 18 September 2021; Accepted 6 October 2021; Published 17 December 2021

Academic Editor: Yang Wu

Copyright (c) 2021 Jinglong Li et al. This is an open access article distributed under the Creative Commons Attribution License, which permits unrestricted use, distribution, and reproduction in any medium, provided the original work is properly cited.

\begin{abstract}
The existence of the weak interlayer of the rock slope changes its mechanical characteristics. To ensure the safety of the slope, it is necessary to analyze the overall stability of the slope. Taking the double-layer weak interlayer rock slope beside 318 National Road in Qiyue Mountain, Hubei Province, as an example, a slope model with a weak interlayer was established through GTS software, and the model was imported into FLAC3D for calculation, and the deformation of the slope by the double-layer soft interlayer was studied. The influence of characteristics and safety factors reveals the controlling effect of the double-layer weak interlayer on the stability of the slope and its failure mode. The potential sliding surface of the slope is determined to be the lower weak interlayer, and the weak interlayer after the anchor cable reinforcement is carried out. Numerical analysis shows that the reasonable application of anchor cables significantly improves slope stability. The research results can provide reference significance for slope stability analysis of similar projects.
\end{abstract}

\section{Introduction}

With the rapid construction of infrastructure in Western China, a large number of rock slopes are distributed along highways and railways. Some rock slopes contain weak interlayers which play a controlling role in slope stability. The occurrence of slope disasters causes a series of safety and environmental problems. Therefore, it is very important to evaluate slope stability with a weak interlayer [1-3].

Currently, many scholars have done some research on this issue. Fan et al. [3,4] studied transfer function and dynamic failure energy identification methods for rock slope with a weak interlayer. Wu et al. [5] studied the reinforcement effect of anchor cable-frame support and determined its role in maintaining slope stability. Chen and Yang [6] studied the dynamic response rules of rock slope with antidip weak interlayer under the seismic wave. Qin [7] analyzed the influence of weak interlayer on slope stability on the engineering side. Feng et al. [8] studied the failure mode of gently inclined bedding slope by the bottom friction method. Some scholars [9-11] used the numerical simulation methods to study the failure mode and stability of rock slope and have achieved more meaningful results. Fu et al. [12] applied the method of mechanical theory analysis to construct the deformation characteristics and failure mechanism of the slope with a weak interlayer. Li and Yang [13] analyzed the monitoring data after excavation of the bedding slope with weak rock in the Xijiafen area of Tongzi County, Zunyi City, and concluded that the slope is in a stable state. Wu et al. [14] took a typical soft interlayer slope on the Shanghai-Chengdu Expressway as an example and compared the corresponding softening model and the ideal elastoplastic model.

In summary, the stability of rock slope with weak interlayer needs further research. Taking the slope of 318 National Highway in Qiyueshan, Hubei Province as an example, this paper closely combines the engineering practice and does numerical simulation based on the project, analyzes the controlling effect of multilayer weak interlayer on slope stability, the mechanism of slope deformation, and stress and then puts forward slope reinforcement scheme. 
This study can provide theoretical and empirical support for similar projects.

\section{General Situation}

The slope of 318 National Highway in Qiyue Mountain has eroded hilly landform with undulating hills. The strata in the slope area are a weathered residual layer, slightly weathered limestone, and limestone. Limestone is hard and has strong weathering resistance. Karst is well developed, and karst fissure water is filled between fissures. Affected by karst water, the local rock mass is weak.

(1) Weathered Residual Layer. This layer's soil property is mainly granular clay which has color of yellowbrown and yellow, the granular composition is mainly silicified shale breccia which has grain size of $1 \sim 2 \mathrm{~cm}$, and grain shape is subedge and subcircle. The content of silicified shale breccia is about 20\% $30 \%$ (wet soft plastic-plastic).

(2) Striated Limestone. Color is yellowish, cyan-grey, and purple-red, the structure is cryptocrystalline tortoise crack shape, and the layer is mediumthick and thick. Two layers of weak interlayer are intercalated in the slope which has main components such as debris, softening mud, and fault gouge.

\section{Calculation Model}

According to the general situation of slope and considering the effect of weak interlayer on slope stability, the slope model with weak interlayer is established by GTS software and imported into FLAC3D for calculation and analysis. The weak interlayer influence on the deformation characteristics and safety coefficient of the slope is analyzed.

The calculation gives different physical parameters to the model rock and the weak interlayer, respectively. The parameters are determined according to the large-scale shear test, as shown in Table 1. In the process of calculation, other factors are appropriately simplified, without considering the role of water.

The calculation model consists of 5498 nodes and 2683 nodes and used the Mohr-Coulomb material model. In the model, three and five parts of soil are weak interlayer parts, which are given parameters to analyze the overall stability of the slope, respectively. The model is shown in Figure 1. Directional constraints are applied to the bottom, left, and right sides of the slope model. Slope model constraints are shown in Figure 2.

\section{Slope Stability Analysis}

4.1. Control Analysis of Weak Interlayer on the Upper Slope. The same parameters of the lower weak interlayer and the surrounding soil are kept, only the upper weak interlayer is retained, and other conditions remain unchanged. Based on these conditions, slope stability is analyzed. Therefore, the influence of the upper interlayer on the slope stability is analyzed and determined whether the upper weak interlayer is the control surface of the slope stability. Under these conditions, the horizontal and vertical displacement distributions of the slope are shown in Figures 3 and 4, respectively.

From Figure 3, the maximum horizontal displacement occurs in the upper rock of a weak interlayer, especially on the lower part empty slope of the upper sliding body. It develops along the interlayer toward both ends, which may form a slip zone along the weak interlayer.

From Figure 4, under the influence of the upper weak interlayer, the upper rock has obvious vertical displacement compared with the slope of other parts. The displacement of the negative direction of the $Z$-axis appears under the influence of self-weight. The maximum vertical displacement occurs at the top of the slope. Under the influence of the weak interlayer, the vertical displacement of the upper rock is larger than that of other parts. Because of the existence of a weak interlayer, the stability of the upper rock becomes worse. The deformation of rock tends to be continuous, and there is no abrupt change in deformation.

The horizontal and vertical stress distributions of the slope are shown in Figures 5 and 6, respectively. The stress distribution of the slope changes with the shape of the slope. From Figure 5, under the natural stress state, the slope is in a local tension state, which occurs in the intersection zone between the weak interlayer and the upper rock, which generally is an unstable region. From Figure 6, the stress distribution of different values is parallel to the slope. Positive value is tension stress, and a negative value is compression stress. Maximum compression stress exists at a certain depth in the slope.

In Figure 7, there is a large shear strain increment along the weak interlayer and surrounding rock, which clearly shows the position of the potential sliding surface of the slope. Figure 8 shows the change of the plastic zone at the weak interlayer. Compared with other parts, there is a more obvious plastic zone along the weak interlayer, most of which is a shear failure. Figure 9 shows that the upper rock displacement of the interlayer is more obvious than that of other parts and also shows the potential displacement slip surface.

The principle of the strength reduction method can be summarized as dividing the internal friction angle $\varphi$ value and the cohesive force $c$ value by the reduction coefficient $F_{\text {si }}$, assuming that the elastic modulus $E$ and Poisson's ratio $v$ remain unchanged, and then input them as new parameters. Through repeated iterative calculation and analysis, the iterative calculation ends when the slope calculation reaches the critical state of maintaining stability. At this time, the corresponding safety factor $F_{s}$ is the minimum safety factor, and the critical sliding surface is obtained at the same time. If the calculated $F_{s}$ is larger, it indicates that the slope to be calculated is safer. The reduction formula of the finite element strength reduction method is shown as follows: 
TABLE 1: Basic physical and mechanical parameters of rock mass.

\begin{tabular}{lccccc}
\hline Lithology & Density $\left(\mathrm{kg} / \mathrm{m}^{3}\right)$ & Cohesive force $(\mathrm{kPa})$ & Friction angle $\left(^{\circ}\right)$ & Bulk modulus $(\mathrm{MPa})$ & Shear modulus $(\mathrm{MPa})$ \\
\hline Rock & 2400 & 1200 & 32 & 16700 & 8870 \\
Weak interlayer 1 & 2000 & 19.6 & 25.4 & 12 & 8 \\
Weak interlayer 2 & 2000 & 26.8 & 26.9 & 12 & 8 \\
\hline
\end{tabular}

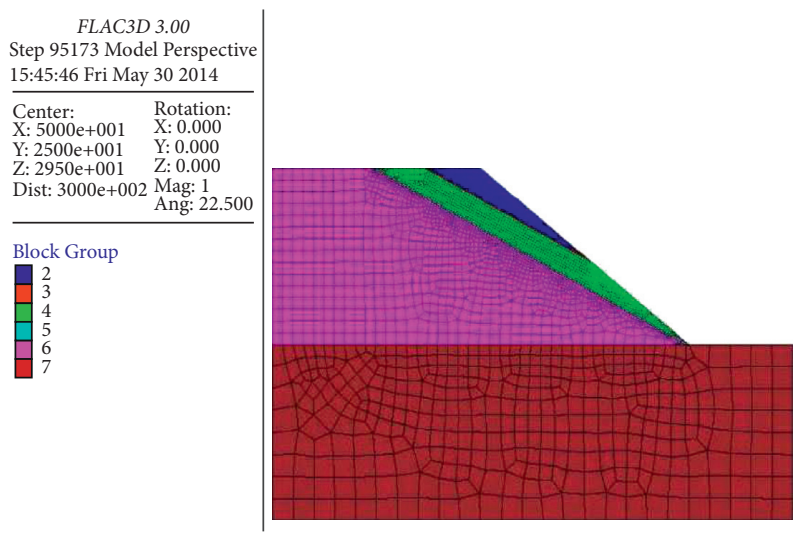

FIgURE 1: Computing model.

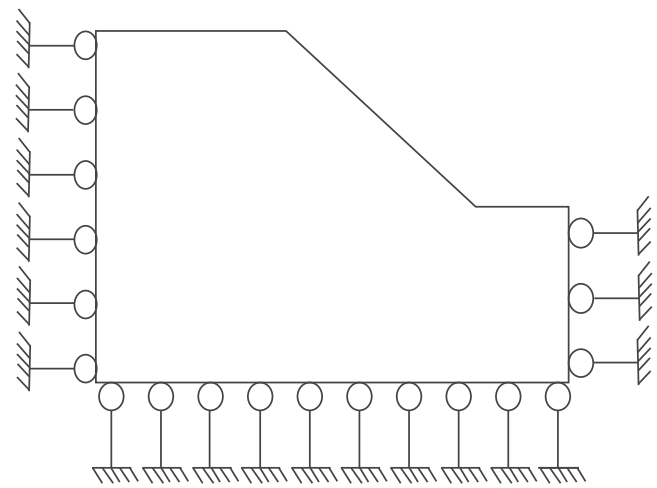

Figure 2: Model constraints.

FLAC3D 3.00

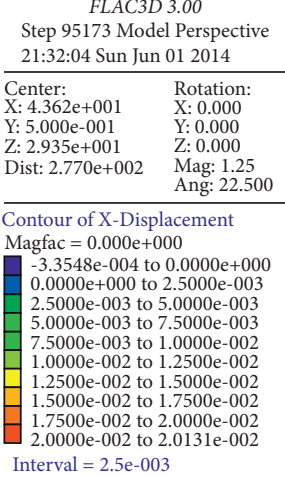

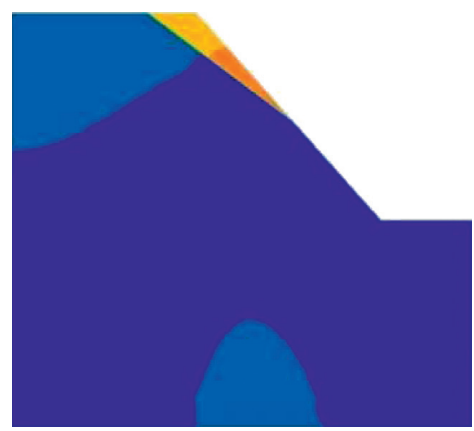

Figure 3: Horizontal displacement diagram.

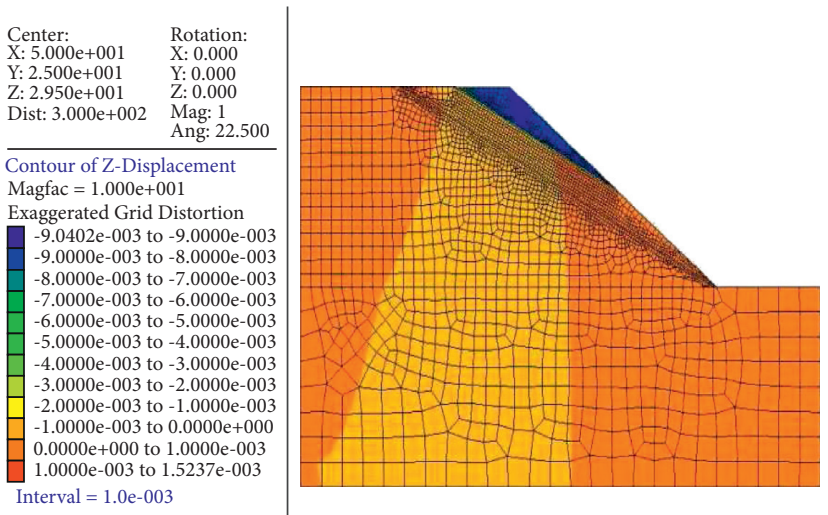

FIGURE 4: Vertical displacement diagram.

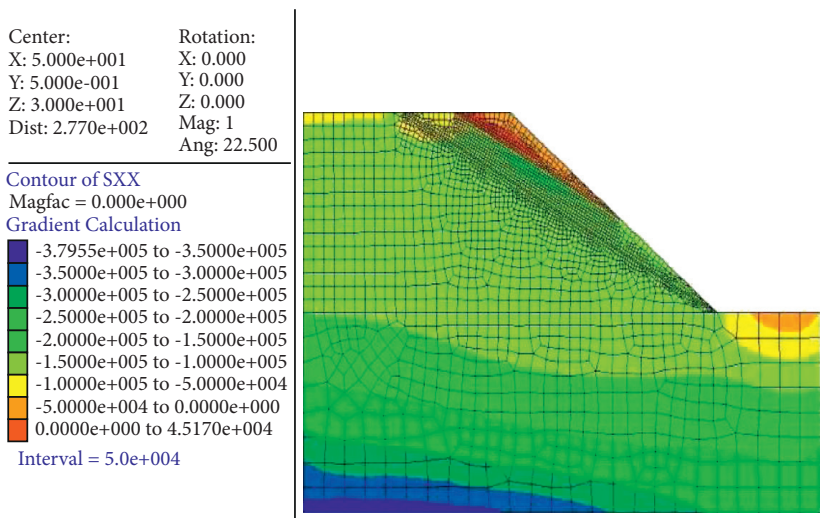

FIgURE 5: Horizontal stress diagram.

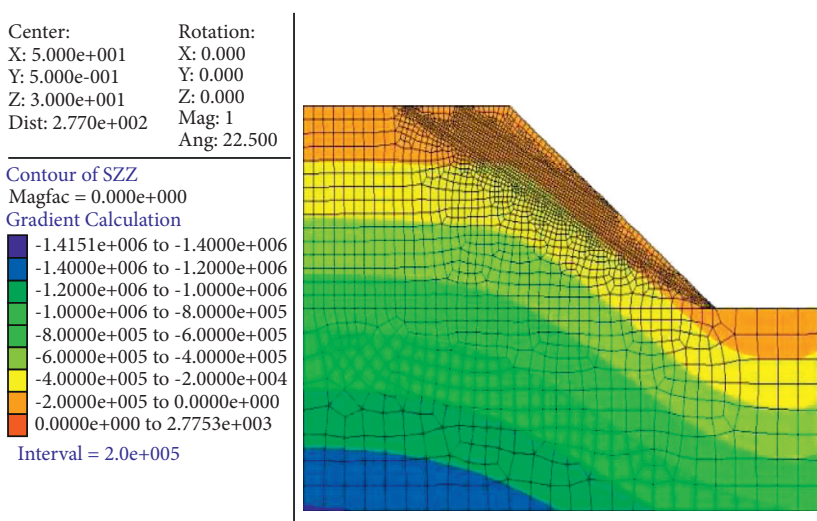

Figure 6: Vertical stress diagram. 


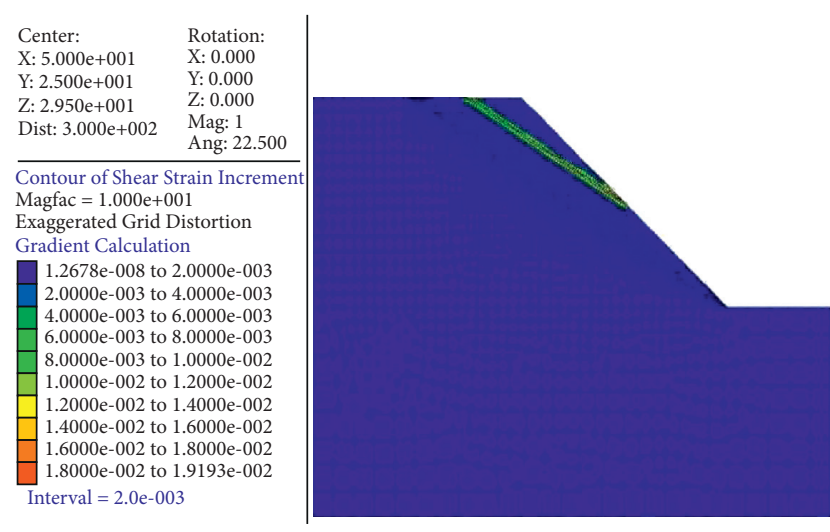

Figure 7: Shear strain increment diagram.

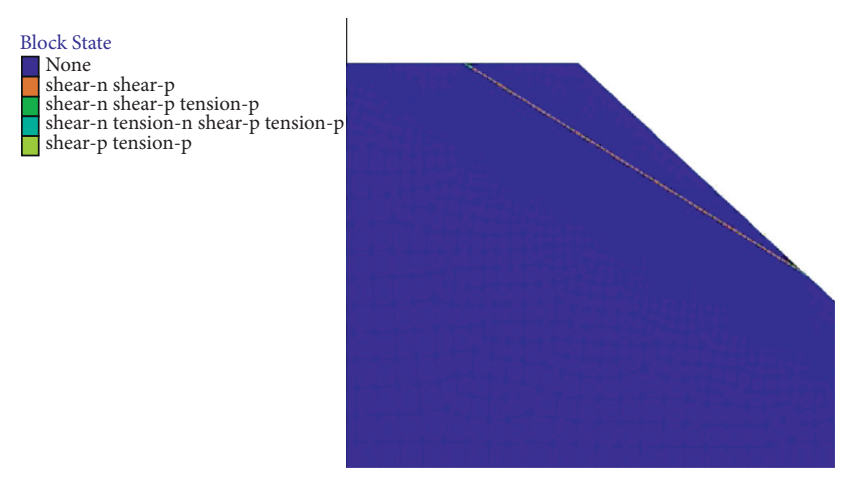

FIgURE 8: The plastic zone.

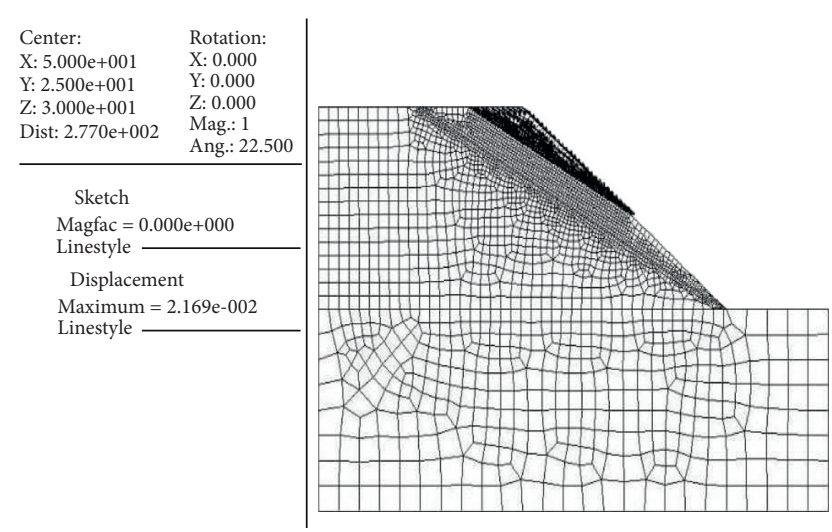

FIGURE 9: Displacement vector diagram.

$$
\left.\begin{array}{rl}
c_{i} & =\frac{c}{F_{\Omega}} \\
\varphi_{i} & =\arctan \left(\frac{\tan \varphi}{F_{\mathrm{si}}}\right) \\
\tau_{i} & =c_{i}+\sigma \tan \varphi_{i}
\end{array}\right\} .
$$

In the formula, $c$ is the cohesive force, $\mathrm{kPa} ; \varphi$ is the internal friction angle, $\left({ }^{\circ}\right) ; \sigma$ is the total stress, $\mathrm{kPa} ; F_{\mathrm{si}}$ is the strength reduction factor; $c_{i}$ is the cohesive force corresponding to the reduction factor $F_{\mathrm{si}}, \mathrm{kPa} ; \varphi_{i}$ is the internal friction angle corresponding to the reduction factor $F_{\mathrm{si}},\left(^{\circ}\right)$; and $\tau_{i}$ is the shear strength corresponding to the reduction factor $F_{\mathrm{si}}$, $\mathrm{kPa}$.

When the slope is unstable, the strength reduction factor $F_{s}$ is the safety factor.

The safety coefficient calculated by the strength reduction method is 1.2 , which is higher than the minimum safety coefficient of the slope in the stable state. The slope stability is good, but the influence of a weak interlayer on the slope stability is small. The deformation vector diagram clearly shows the position of the potential sliding surface of the slope. The analysis and simulation of the upper weak interlayer accord with the actual situation of practice.

4.2. Control Analysis of Weak Interlayer on the Lower Slope. The same parameters of the upper weak interlayer and the surrounding soil are kept, only the lower weak interlayer is retained, and other conditions remain unchanged. Based on these conditions, the influence of the lower interlayer on the slope stability is analyzed and determined whether the lower weak interlayer is the control surface of the slope stability. Under these conditions, the horizontal and vertical displacement distributions of the slope are shown in Figures 10 and 11 , respectively.

From Figure 10, the maximum horizontal displacement occurs at the slope foot position. The upper rock of the weak interlayer has a larger displacement than other parts; the closer to the slope foot, the greater the displacement; it develops along the interlayer toward both ends, which may form a slip zone along the weak interlayer.

From Figure 11, the displacement of the negative direction of the $Z$-axis appears under the influence of selfweight. The maximum vertical displacement occurs at the top of the slope. Under the influence of the weak interlayer, the vertical displacement of the upper rock is larger than that of other parts. Because of the existence of a weak interlayer, the stability of the upper rock becomes worse. The deformation diagram can clearly show the position of the slope potential sliding surface.

Slope horizontal and vertical stress distributions are shown in Figures 12 and 13, respectively. From Figure 12, we can see the horizontal stress distribution of the slope. There is larger tension stress along the weak interlayer upper part, while there is a larger compression stress concentration at the slope foot position. Different colors in the figure indicate the change of stress. A positive value is tension stress, and a negative value is compression stress. The maximum compression stress in this area exists at the slope foot position. From Figure 13, the same stress distribution is parallel to the slope. The different colors in the figure indicate the change of stress. The maximum vertical compression stress in this region exists at a certain depth in the slope.

Figure 14 shows that there is a large shear strain increment along the weak interlayer and surrounding rock. It also has a large shear strain increment at the slope foot position and a large shear increment along the weak interlayer lower part. The potential slope sliding surface is clearly shown. As we can see from Figure 15, compared with 


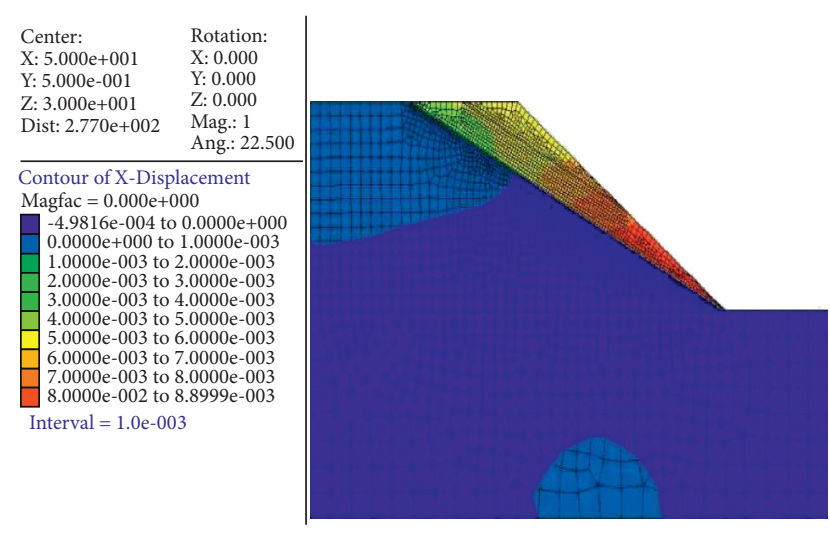

Figure 10: Horizontal displacement diagram.
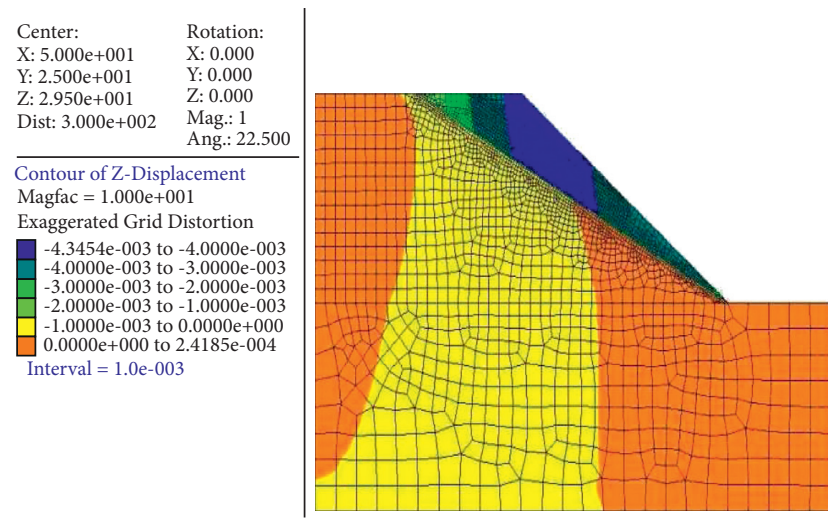

FIGURE 11: Vertical displacement diagram.

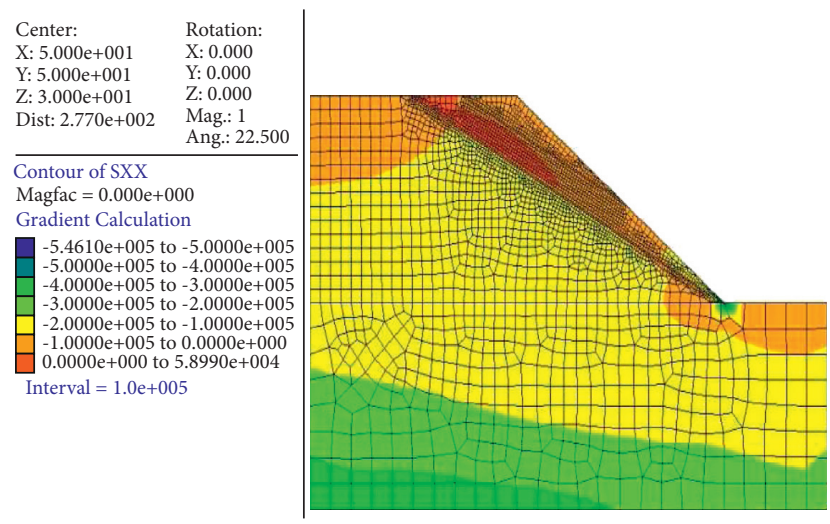

Figure 12: Horizontal stress diagram.

slope other parts, the plastic zone along the weak interlayer is more obvious, and most of which are a shear failure. It shows that the existence of the weak interlayer makes the surrounding rock become deformed obviously. Figure 16 shows that the interlayer displacement of the upper rock is more obvious than that of other parts and also shows the potential displacement slip surface.

The safety coefficient calculated by the strength reduction method is 1.05 , which is close to the minimum safety coefficient in a stable state and is on the verge of stability. The deformation vector diagram clearly shows

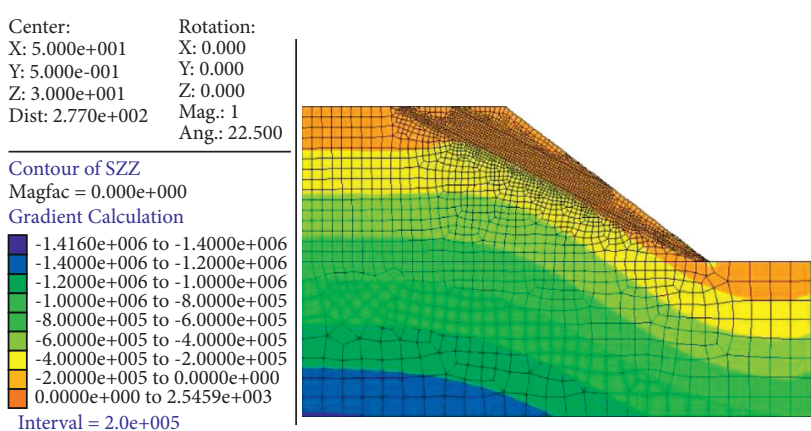

Figure 13: Vertical stress diagram.

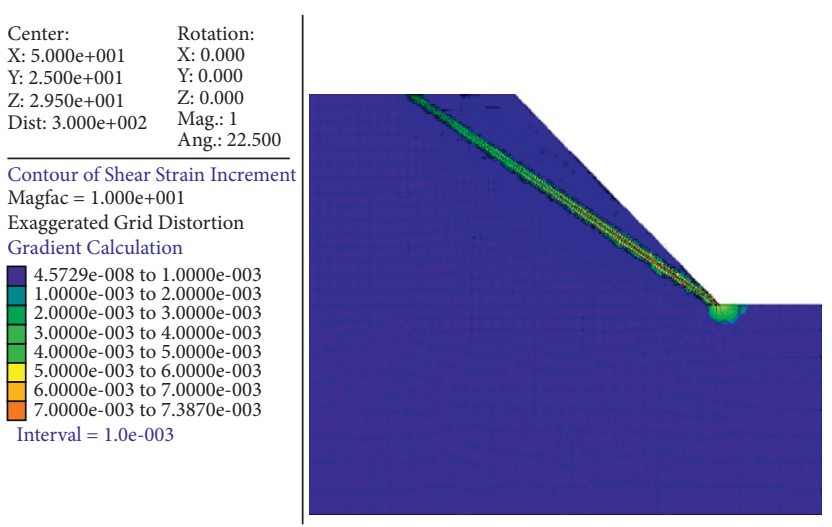

FIgURE 14: Shear strain increment diagram.

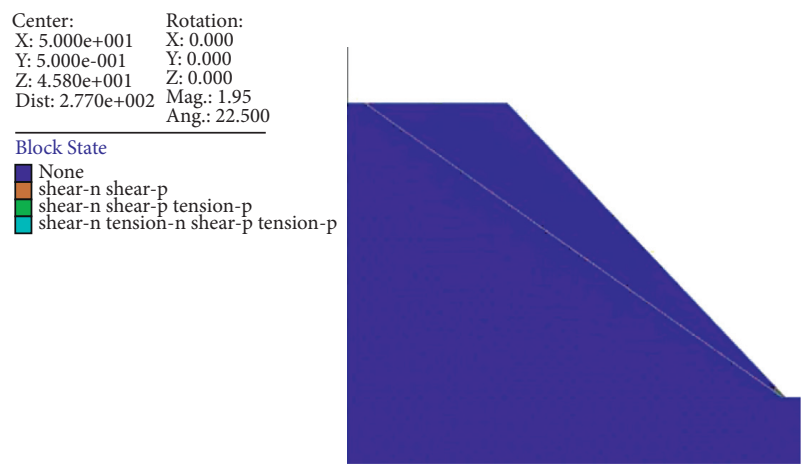

FIgUre 15: The plastic zone.

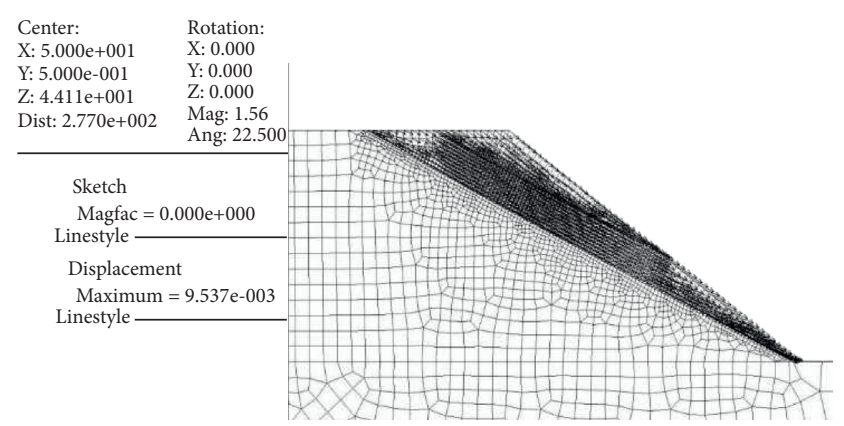

FIGURE 16: Displacement vector diagram.

the position of the potential sliding surface of the slope. The analysis and simulation of the lower weak interlayer accord with the actual situation of practice. Because the 
slope is on the verge of stability, it is necessary to reinforce the slope.

4.3. Simulation Analysis of Entire Stability. Different parameters are assigned to the upper and lower weak interlayer to do the model calculation. The corresponding parameters are given to the upper and lower weak interlayer, respectively, and the influence of slope stability control surface and potential sliding surface on the slope is studied. The horizontal and vertical displacement distribution of the slope is shown in Figures 17 and 18, respectively.

From Figure 17, under the influence of the upper and lower weak interlayers, along the lower part of the two weak interlayers, the displacement of rock is relatively large. The nearer to the slope foot position, the greater the displacement. Developing along the interlayer toward both ends, a slip zone along the weak interlayer may be formed.

From Figure 18, the maximum vertical displacement occurs at the top of the slope, mainly in the upper rock of the weak interlayer. Due to the low strength and relatively high compression stress of the weak interlayer, the large vertical displacement of the upper part of the weak interlayer occurs. The upper rock of slope is affected by the weak interlayer, especially affected by two weak interlayers; the vertical displacement is larger than that of other parts. Because of the existence of a weak interlayer, the stability of the upper rock becomes worse. The deformation diagram can clearly show the position of the potential sliding surface of the slope.

The horizontal and vertical stress distributions of the slope are shown in Figures 19 and 20, respectively. From Figure 19, there is large tensile stress along the upper part of the weak interlayer. Affected by two weak interlayers, the area is larger than that of one weak interlayer, while there is a large concentration of compression stress at the slope foot position. The maximum compression stress in this region exists at the slope foot position. From Figure 20, the same stress distribution is parallel to the slope, and the different colors showed the change of stress. The maximum vertical compression stress in this region exists at a certain depth in the slope.

Figure 21 shows that there are large shear strain increments along with two weak interlayers and surrounding rock. The shear strain increment along the upper weak interlayer mainly concentrates on the lower part of the interlayer. The shear strain increment along the lower weak interlayer almost runs through the whole weak interlayer. At the same time, there is a large shear strain increment at the slope foot position. The position of the potential sliding surface of the slope is shown. There are obvious plastic zones along with the two weak interlayers in Figure 22, most of which are shear failures. From Figure 23, the displacement of the two interlayers is obvious.

The safety coefficient calculated by the strength reduction method is 1.05 , which is close to the minimum safety factor of the slope in the stable state. It is concluded that the slope is on the verge of stability. The deformation vector diagram clearly shows the position of the potential sliding surface of the slope. The analysis and simulation of the lower

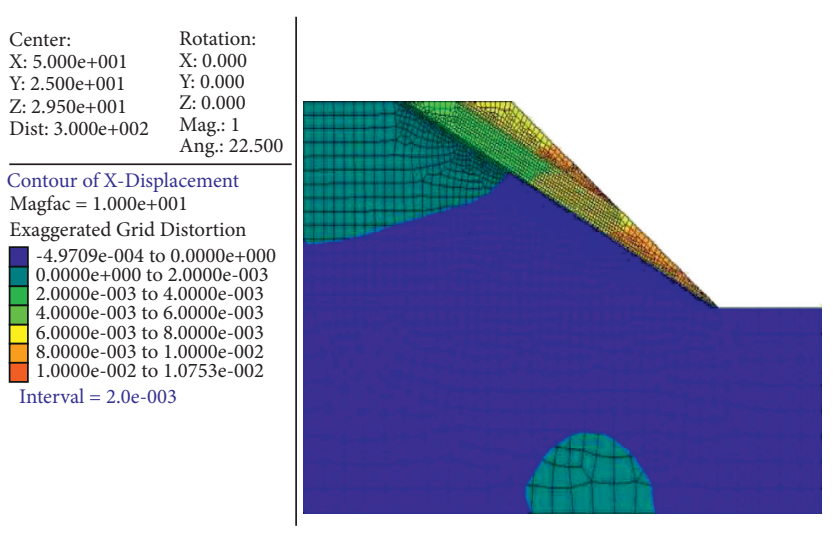

FIGURE 17: Horizontal displacement diagram.

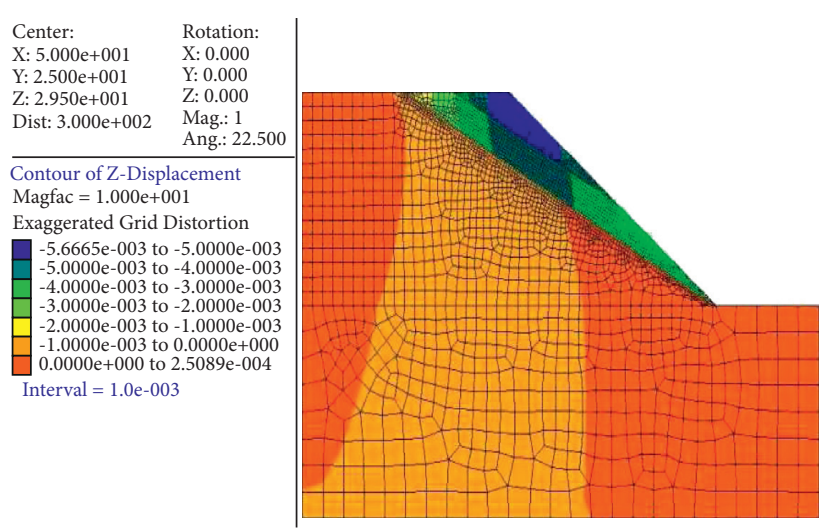

Figure 18: Vertical displacement diagram.

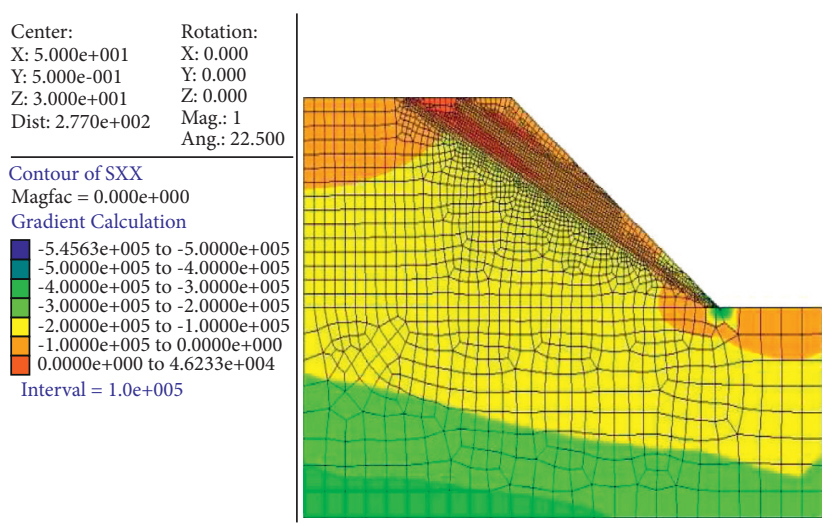

Figure 19: Horizontal stress diagram.

weak interlayer accord with the actual situation of practice. Because of the importance of slope stability, measurement should be taken to improve slope stability.

\section{Stability Analysis of Slope Reinforcement with Weak Interlayer}

5.1. Numerical Simulation of Prestressed Anchor Cable. The anchor cable used at the project site and its layout method is taken as an example. FLAC3D software is used to simulate the reinforcement measures of prestressed anchor cables to 


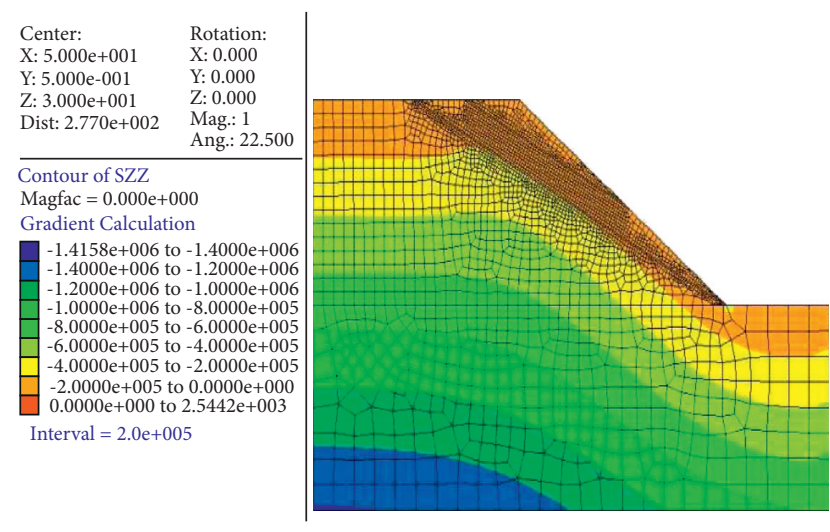

FIgURE 20: Vertical stress diagram.

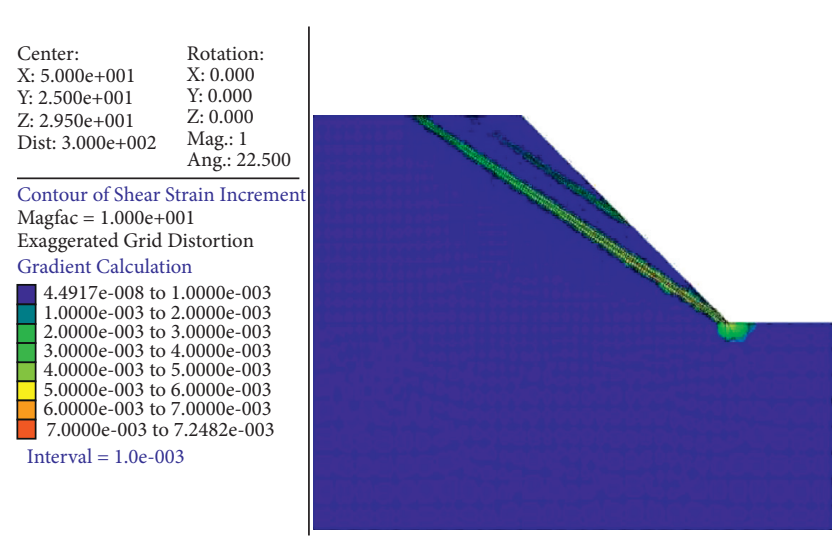

FIgURE 21: Shear strain increment diagram.

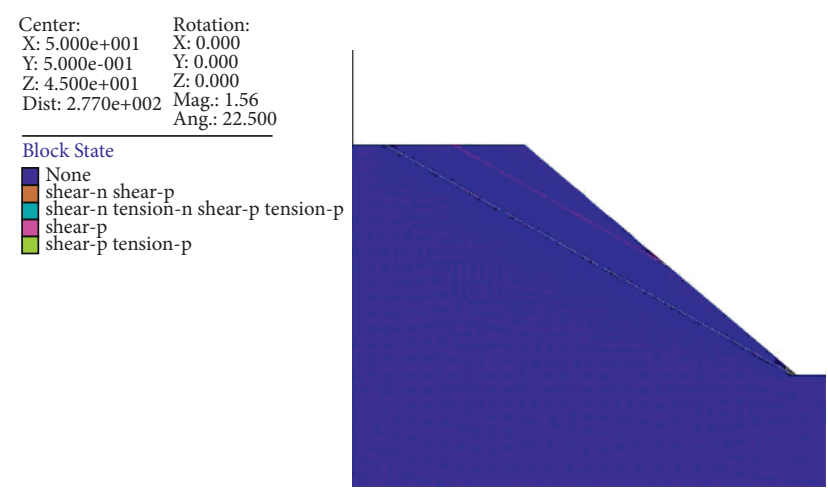

Figure 22: The plastic zone.

reinforce the slope. According to the numerical model of the slope, 8 anchor cables are applied to the model. The length of the anchor cables is $22 \mathrm{~m}$ which has free section of $14 \mathrm{~m}$ and the anchor section of $8 \mathrm{~m}$. The prestress is $700 \mathrm{kN}$ which is applied in the free section. Horizontal and vertical spacing of the anchor cables is $4 \mathrm{~m}$, and the distance between the top anchor cables and the slope top is $8 \mathrm{~m}$. The arrangement angle is $40^{\circ}$ (Figure 24). The reinforcement effect of the anchor cable is evaluated by calculation. Then, the corresponding reinforcement measurement is put forward.

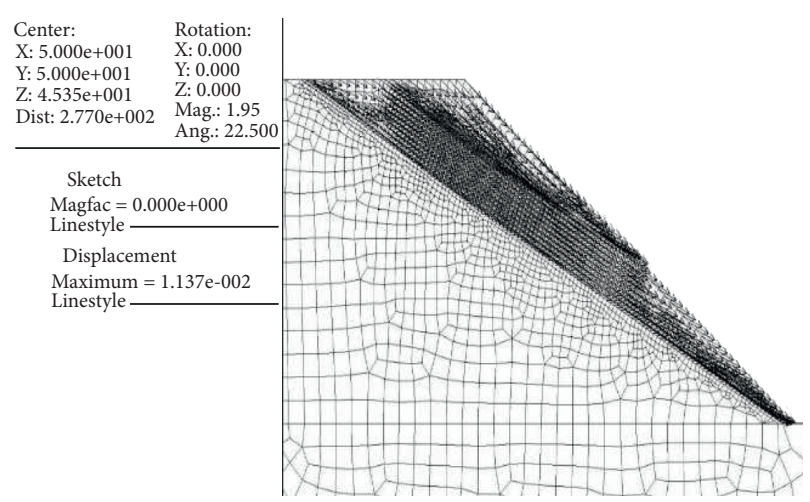

Figure 23: Displacement vector diagram.

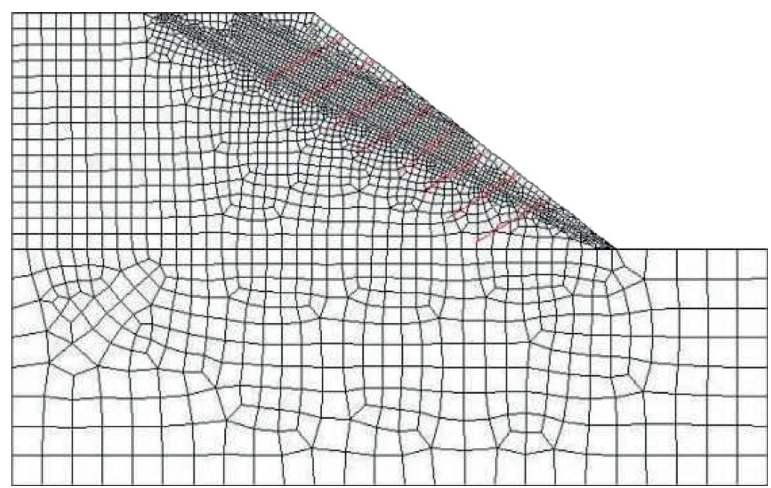

FIGURE 24: Slope model with anchored cables.

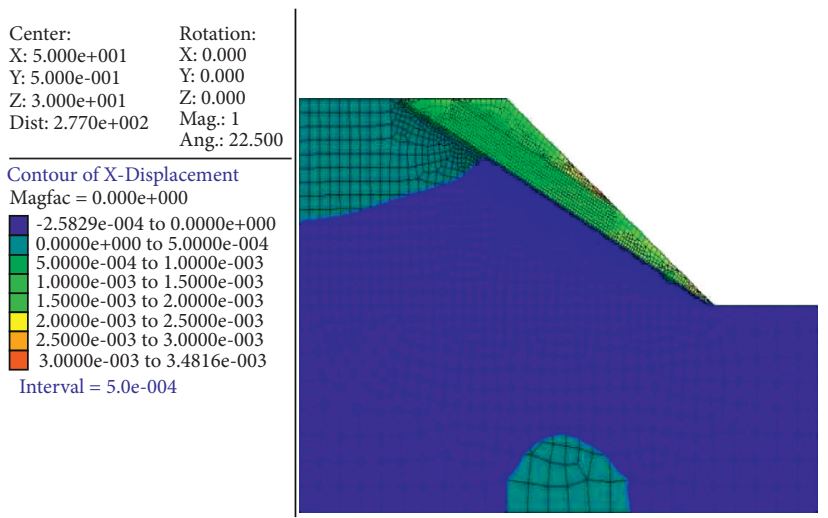

FIgURE 25: Horizontal displacement diagram after application of the anchor cable.

5.2. Analysis of Reinforcement Effect of Prestressed Anchor Cable. From Figure 25, the displacement from weak interlayer to the slope is reduced after the anchor cable is applied, and there is only a small maximum displacement zone. From Figure 26, the vertical displacement of the weak interlayer decreases significantly when the anchor cable is applied. From Figure 27, a plastic zone exists in the weak interlayer and slope area before and after anchor cable reinforcement, and the shear strain area decreases, and the maximum shear strain increment decreases. 


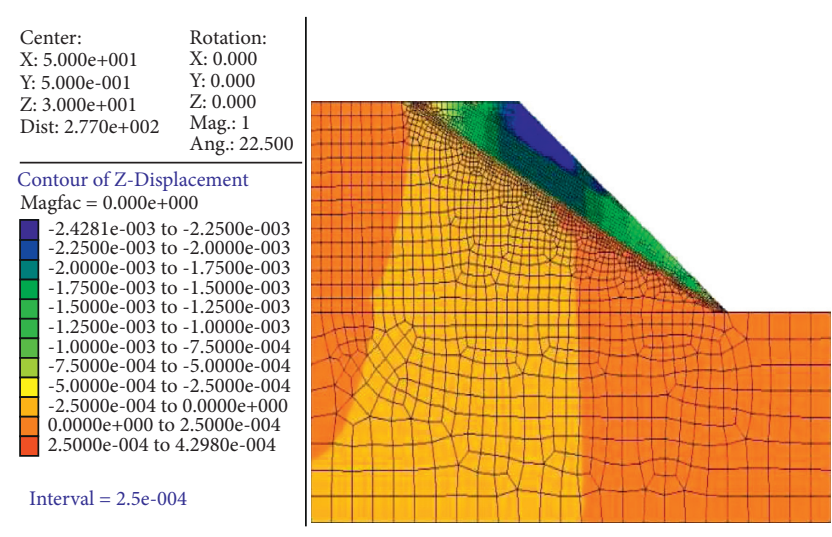

FIgURE 26: Vertical displacement diagram after application of the anchor cable.

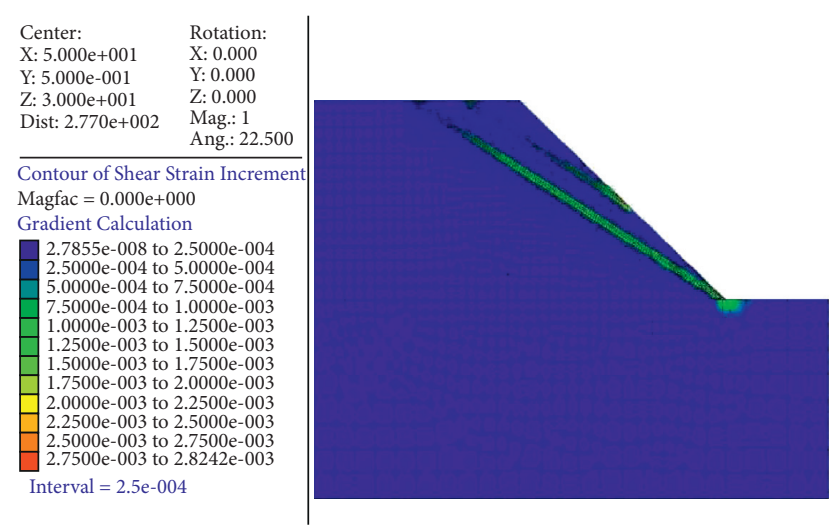

Figure 27: Incremental shear strain diagram after anchor cable application.

The safety coefficient calculated by the strength reduction method after the anchor cable is applied is 2.2, which can effectively guarantee the safety requirements. The safety coefficient of the weak interlayer slope without anchor cable is 1.05. The reinforcement of the anchor cable significantly improves the stability of the slope.

\section{Conclusion}

The numerical model is established based on the rock slope with a multilayer weak interlayer. The influence of upper and lower weak interlayer on slope stability is considered comprehensively. Conclusions are as follows:

(1) The weak interlayer plays a controlling role in slope stability. When the slope is damaged, the position of the weak interlayer has been sliding or has a large displacement, and the shear yield stress usually occurs at the position of the weak interlayer.

(2) The stability of slope with multilayer weak interlayer is controlled by the state of the main weak interlayer. The lower weak interlayer is the main controlling factor, and the slope is on the edge of stability and lacks sufficient safety reservation.
(3) Reinforcing rock slope with weak interlayer by prestressed anchor cable can effectively improve the integrity of the slope and reduce the occurrence of geological disasters such as landslides.

\section{Data Availability}

The data used to support the findings of this study are included within the article.

\section{Conflicts of Interest}

The authors declare that they have no conflicts of interest regarding the publication of this paper.

\section{Acknowledgments}

The work was supported by Key Laboratory of Geological Hazards on Three Gorges Reservoir Area China Three Gorges University) (2018KDZ03) and National Natural Science Foundation of China (51909142).

\section{References}

[1] H. Z. Li, B. Bin, X. L. Chen, Y. Yao, and Y. J. Mao, "Stability analysis on the gently-inclined stepped slope with weak interlayer under hydraulic action," Mining Research and Development, vol. 37, no. 11, pp. 41-45, 2017.

[2] X. X. Liu, Y. Hou, Y. Dai, P. Zhang, and J. Jia, "Study on longterm stability of weak interlayer rock slope," Journal of China \& Foreigh Highway, vol. 37, no. 4, pp. 21-24, 2017.

[3] G. Fan, J. J. Zhang, and X. Fu, "Reasearch on transfer function of bedding rock slope with soft interlayers and its application," Rock and Soil Mechanics, vol. 38, no. 4, pp. 1052-1059, 2017.

[4] G. Fan, J. J. Zhang, X. Fu, Z. J. Wang, and H. Tian, "Energy identification method for dynamic failure mode of bedding rock slope with soft strata," Chinese Journal of Geotechnical Engineering, vol. 38, no. 5, pp. 959-966, 2016.

[5] S. J. Wu, Y. J. Jiang, T. Deng, and Z. C. Guan, "Seismic responses of weak interlayered slope with anchorframe reinforcement using model slope on shaking table," Journal of Engineering Geology, vol. 25, no. 4, pp. 1065-1072, 2017.

[6] Z. L. Chen and X. Q. Yang, "D ynamic responses of a rock slope with counter-tilt weak intercalation layer under seismic loads," Applied Mathematics and Mechanics, vol. 36, no. S1, pp. 155-156, 2015.

[7] H. Qin, "Analysis of deformation characteristics and its influencing factors of slope with soft interlayer," Journal of Chongqing University(Natural Science), vol. 30, no. 2, pp. 282-286, 2011.

[8] W. K. Feng, Y. C. Shi, H. J. Chai, X. G. Feng, and B. Lin, "Study of mechanism of deformation failure of a low-angle bedded high slope with physical simulation method," China Journal of Highway and Transport, vol. 17, no. 2, pp. 32-36, 2004.

[9] X. Z. Chen, H. M. Tang, Y. C. Yang, B. Hu, and J. Ni, “3D analysis of landslide stability based on strength reduction FLAC 3D," Hydrogeology\&Eingeering Geology, vol. 35, no. 2, pp. 24-29, 2008.

[10] Q. Zhang, N. Li, F. F. Chen, and G. Swoboda, "Practical method to simulate thickness of weak interbed and its application," Chinese Journal of Rock Mechanics and Engineering, vol. 21, no. 1, pp. 2637-2644, 2010. 
[11] Y. Wang and C. F. Li, "Study on stability evaluation technology of inclined bank slope with weak interlayer," Journal of China\&Foreign Highway, vol. 33, no. 5, pp. 19-23, 2013.

[12] Y. Fu, Z. Wang, F. Wan, and Z. Hongqing, "Research and evaluation of upper bound analysis method for slope stability with weak layer," Metal Mine, vol. 49, no. 12, pp. 38-43, 2020.

[13] H. Li and J. Yang, "Deformation characteristics and stability evaluation of bedding slope with weak interlayer," Journal of Geological Hazards and Environment Preservation, vol. 32, no. 2, pp. 50-54, 2021.

[14] K. Wu, Z. Zheng, and H. Yu, "Stability evaluation of highway slope with soft LayerBased on strain softening characteristics," Geological Science and Technology Information, vol. 38, no. 6, pp. 150-156, 2019. 